\title{
Political culture and tobacco control: an international comparison
}

\author{
David Vogel, Robert A Kagan, Timothy Kessler
}

\begin{abstract}
This article describes and compares the politics of tobacco regulation in four industrial democracies: the US, Canada, France, and Japan. We argue that the degree and type of cigarette control has varied among these countries and that these contrasts reflect different political and cultural traditions concerning individual rights and the proper role of government, as well as differences in government structure. The US is widely regarded as having a highly individualistic culture, suspicious of government control over civil society. In contrast, Japan is a hierarchical society, in which individual preferences are generally subordinated to group needs and state authority. France resembles Japan in its elitist decision-making and low level of group participation, but also differs in that it does not pursue social consensus or devalue individualism. Canada, like the US, is characterised by more group participation than France or Japan, but is more willing than the US to let government define and pursue collective goals.

These factors have played a major role in determining the scope and target of tobacco controls implemented in each country. We identify three types of tobacco regulation: informational, paternalistic, and protective. Because the four countries have such different conceptions as to what constitutes the appropriate scope of governmental authority and responsibility, there is significant variation in the types of tobacco control they have adopted.
\end{abstract}

(Tobacco Control 1993; 2 : 317-26)

\section{Introduction}

This article attempts to explain significant variations in the type of tobacco control regulation imposed upon both citizens and corporations in four industrial democracies: the US, Canada, France, and Japan. It seeks to account for why the rights and responsibilities of smokers and non-smokers are defined differently among the cases, and why tobacco companies of each nation face varying degrees of government restrictions. We begin with an overview of the public policy issues surrounding tobacco regulation, and then turn to analyses of our four country-cases. We con- clude by analysing what is distinctive about the US.

Public policies towards smoking: an overview

In virtually all wealthy, industrialised democracies, there is a large potential political constituency in favour of strict tobacco regulation. Many people in these countries have become aware of smoking's health hazards, and millions have stopped smoking. Practically everyone has family or friends who have suffered or died from lung cancer or emphysema. Many smokers want to stop but have failed to do so. And finally, millions of nonsmokers regard smoking in public places and worksites as both annoying and hazardous. But while many would prefer tougher legal restrictions on tobacco, their power is limited by the classic "collective action" problem: the benefits to each individual do not warrant the effort and personal costs of political activism. Effective legislation, therefore, has generally come about through aggressive and talented leadership - what James Wilson' calls "entrepreneurial politics". That leadership stems from a variety of sources: public health officials, university researchers, disease prevention organisations, anti-tobacco and non-smokers' rights lobbies, as well as politicians.

Naturally, these activists find their cause challenged by powerful opponents. In each of our four countries, the tobacco industry is large, profitable, and well-represented. In the US and Canada, cigarette manufacturing is dominated by a few huge companies, whose diversification into food products has made them even more important employers. In Japan and France, until recently state-owned monopolies have controlled production. Each government receives substantial revenues from cigarette taxes, while tobacco advertising supports print media, advertising agencies, fine arts, and sporting events. Tobacco companies are also major campaign contributors and fund permanent lobbies to protect their interests. At the individual level, millions of smokers resent governmental attempts to change long-established lifestyles, the intensity of their preferences often exceeding that of smoking opponents. In sum, tobacco is politically potent.

Anti-smoking activists have sought to shift the burden of responsibility from smoker to producer. They claim that massive advertising reduces the effectiveness of warnings - especi- 
ally for unwitting and impressionable youngsters. In addition, they point out that tobacco is even more addictive than alcohol. Finally, they argue that while alcohol is dangerous only when "abused," cigarettes can kill even "when used as directed." Portraying tobacco companies as "drug pushers," smoking opponents maintain that the government must go beyond the liberal state's responsibility to make information available, and assume a more paternalistic role, discouraging smoking. Activists have thus demanded a total ban on cigarette advertising, plus larger and more explicit warning labels. They have also advocated higher taxation levels to both discourage smoking and fund anti-smoking campaigns.

The tobacco industry has, of course, rejected these ideas, offering arguments and research suggesting that advertising neither affects smoking rates nor confuses people about health risks, that high taxation penalises the poor, that advertising restrictions on legal products threaten free speech, and that government controls curb individual freedom. Many voters and officials have been receptive to these arguments.

Both the timing and the objectives of smoking regulation have varied significantly from government to government. In understanding the nature and timing of these differences, it is useful to distinguish between these types of tobacco restrictions:

Type I-Informational: Regulations in this category are primarily aimed at improving risk information available to smokers. These include explicit health warning label requirements, as well as bans on broadcast advertising.

Type II-Paternalistic: Regulations in this category seek to "save smokers from themselves." They include large tax increases to induce smokers to quit and non-smokers to abstain, as well as limits on access to cigarettes, such as bans on cigarette vending machines. Furthermore, premised on the notion that many consumers do not sufficiently attend to blandly presented information about risk, or are too easily seduced by attractive advertising, paternalistic measures also include larger and more frightening warning labels, bans on billboard and print media advertising, and restrictions on tobacco company product sponsorship.

Type III-Protective: Regulations in this category seek to protect non-smokers from smokers. They have primarily consisted of restrictions on actual tobacco use in specific areas, in order to reduce involuntary exposure to "secondhand" or "passive" smoke.

All four countries have imposed regulations that fall into each category. However, the timing and priority they have accorded to each has varied substantially.

\section{Tobacco politics in the US}

The US is widely regarded as having a highly individualistic political culture, suspicious of governmental power and restrictions on market relations. This would suggest that the US might be a slow and weak regulator of the tobacco industry. However, the US also has perhaps the most "health conscious" and moralistic culture in the industrialised world. With a history of prohibition of alcoholic beverages, punitive environmental lawsuits, and cholesterol counting, the US record might well lead one to expect strict tobacco regulation. In actuality, as we will see, the tradition of American individualism has been a twoedged sword, employed both to advance the rights of non-smokers and to protect smokers from government paternalism.

In the 1950s and early 1960s, despite increasing medical evidence about tobacco dangers, neither federal governmental agencies nor Congress did anything to curb the sale or promotion of cigarettes. ${ }^{2,3}$ However, in the mid-1960s, the case for federal intervention suddenly became much stronger. During the Kennedy and Johnson administrations, Congress began to exert federal power in areas traditionally left to local governments or to the market, enacting legislation on racial and sex discrimination, public education, poverty relief, pharmaceutical testing, and safety design for motor vehicles. Thus, when the Public Health Service implicated cigarettes as causes of cancer and heart disease in the 1964 Surgeon General's report, Congress was responsive, passing the Cigarette Labeling and Advertising Act in 1965, which instituted a weak health warning on cigarette packages; and the Public Health Cigarette Smoking Act in 1969, which imposed a broadcast cigarette advertising ban and which strengthened the warning label requirements.

Whether due to this Type I regulation, increased health risk information, or cultural change, the prevalence of American smoking declined markedly in the 1970 s and $80 s^{4,5}$ By 1987, only $27 \%$ of American adults smoked, compared with $37 \%$ in 1970 and $42 \%$ in $1967 .^{6,7}$ Moreover, by 1985 , fully $94 \%$ of Americans believed smoking was hazardous. Smoking was losing glamour, and was increasingly perceived as a nuisance, if not an outright danger.

Nevertheless, cigarettes hardly disappeared; 50 million smokers contributed to 300000 premature cancer and heart disease deaths per year in the early 1980s. Furthermore, teens, young women, and the poor continued to smoke at high rates. Consequently, antismoking activists called for more aggressive measures. In 1984, Congress expanded Type I regulations, prescribing starkly explicit rotating cigarette package warning labels, and extended that requirement to smokeless tobacco in $1986 .^{8,9} \mathrm{By}$ and large, however, the tobacco industry was able to prevent the federal government from enacting paternalistic Type II regulations; the government refused to ban print media advertising, to impose large tax increases on cigarettes, to subsidise antismoking advertisement campaigns, to end tobacco subsidies, or to reduce US government efforts to open up foreign markets to American cigarette exports.

On the other hand, the anti-smoking lobby was successful in expanding Type III regula- 
tions aimed at protecting non-smokers in the workplace, transport facilities, and other public places. In 1986, the General Services Administration, responsible for office space for 890000 federal employees, restricted smoking to designated areas to protect non-smokers from involuntary exposure to tobacco smoke. The Defense Department prohibited smoking in common work areas and launched an antismoking campaign in the armed forces. ${ }^{2}$ The Veterans Administration made its medical centres smoke free. In 1987, smoking was banned on all domestic flights of two hours or less; two years later Congress banned smoking on all domestic flights. ${ }^{10}$ In 1990 , the Interstate Commerce Commission banned smoking on all regularly scheduled buses.

However, the most far-reaching nonsmokers' rights laws were enacted at the local, rather than federal level. In the late 1970s and 1980 s, scores of grass-roots pressure groups emerged throughout the country. Often nicknamed "GASP" (Group Against Smoking Pollution) they differed from the major public health lobbies, which traditionally have been concerned with protecting smokers. The GASPs saw their constituency as non-smokers, and identified themselves with the environmental movement. As one leading activist ${ }^{11}$ put it:

"Activists should state that they are not 'antismoker' but rather environmentalists concerned with clean indoor air for everyone. The issue should be framed in the rhetoric of the environment, toxic chemicals and public health rather than the rhetoric of saving smokers from themselves..."

Like many environmental groups, the GASPs adopted a populist tone, branding tobacco companies as killers and demanding legal rights to smoke-free air. Extending their campaign beyond non-smokers' rights, they eventually also called for more stringent Type II paternalistic measures, such as restricting vending machine sales to limit minors' access, eliminating tobacco advertising and promotion, and imposing higher excise taxes. In 1988, for example, Americans for Nonsmokers' Rights (ANR) and other health groups bypassed California's state legislature and successfully sponsored a referendum that substantially increased cigarette taxes and mandated that some of those revenues be used for an anti-smoking media campaign. In recent years, dozens of cities (including Atlanta, Boston, Chicago, and Dallas) have banned the free distribution of tobacco products as a promotional technique.

Impressive as some of these Type II regulation victories were, local activists' most spectacular successes were in Type III restrictions of tobacco use-especially at the municipal level, where they could outflank the tobacco industry's financial and lobbying advantages. The campaign for local "spot zoning" measures received a tremendous boost from the 1986 Surgeon General's Report, which asserted that prolonged exposure to secondhand smoke elevated the health risks associated with smoking itself. ${ }^{12}$ In 1990, the
US Environmental Protection Agency (EPA) reported that passive smoking results in 3800 deaths annually ${ }^{13,14}$ (an estimate later revised to 3000 ). By 1990 , most states had enacted laws restricting smoking in the workplace and other public places, while an estimated 450 communities had passed their own ordinances, often far stricter than state-level enactments..$^{15}$ While many of these laws segregated smokers in restaurants and other public places, the trend in the workplace has been toward a totally smoke-free environment.

\section{Tobacco politics in Canada}

In the late $1960 \mathrm{~s}$, well after publication of the US Surgeon General's 1964 Report, a Canadian parliamentary committee recommended Type I legislation: restricting tobacco advertising and promotion and requiring warning labels. After considerable pressure from Canada's tobacco manufacturers and growers, the bill was withdrawn and the industry voluntarily agreed to print mild health warnings on each pack, and to refrain from broadcast advertising. ${ }^{16,17}$ Until the late 1980 s, any efforts to enact more stringent legislation were successfully challenged by Canada's extremely profitable and well-connected tobacco industry. However, by 1991, Canada led the world in paternalistic Type II restrictions on cigarette marketing and use-inhibiting taxation levels. It restricted advertising in arts or sport events, and on non-tobacco products, such as t-shirts and mugs. ${ }^{18}$ The 1988 National Taxation Products Control Act banned all cigarette ads in print media (except foreign publications), as well as in billboards and transit posters (as of January 1991). In the spring of 1989, Canada's cigarette tax increased by $80 \%$, and by another $60 \%$ in 1991 . Federal, provincial, and local taxes now comprised more than $75 \%$ of the price of cigarettes; a packet in Canada costs almost $\$ 6.00$ (US currency), compared to about $\$ 1.70$ in the US.

Canada also enacted extensive Type III regulations. Smoking in many private workplaces was regulated, while many municipalities passed "spot zoning" restrictions. The 1988 Non-Smokers' Rights Act banned smoking (except in designated areas) on all federal property, domestic flights, bus and train services, and transport facilities.

Why did Canada end up enacting stronger paternalistic anti-tobacco measures than the US? The answer, we believe, lies in both political culture and structure. Canadian political culture is often sharply contrasted with that of the US, beginning with its colonial choice to remain within the British empire and under its monarchy. Comparing the two nations, Lipset ${ }^{19}$ finds that whereas the American political creed is characterised by antistatism, individualism, populism, and egalitarianism, "Canada has been and is a more class-aware, elitist, law-abiding, statist, collectively oriented and particularistic (group oriented) society..." Public opinion surveys indicate that Canadians tend to be more accepting of governmental authority and con- 
trol. In the same vein, The Economist observes: "The American Declaration of Independence, Canadians are fond of pointing out, emphasised individuals' inalienable rights... while non-revolutionary Canada's founding document stressed the goals of 'peace, order and good government.",20 Canadians' more interventionist political attitudes are reflected in a variety of policy areas : the Canadian government pays proportionally more health bills than the US, has more complete welfare state benefits, more subsidised housing, college student funding, and public retirement benefits. ${ }^{21}$ Government spending as a proportion of gross national product (GNP) is almost $25 \%$ higher than in the US, ${ }^{19}$ and corporate and sales tax levels are also much higher. ${ }^{20}$

Canada's tobacco control experience suggests a puzzle: since Canada embraces more assertive government, why did its original Type I tobacco control legislation lag behind American informational regulation in stringency, and why didn't its aggressive Type II programme begin sooner? We believe the answer relates to the process by which smoking became defined as a social problem, at both the elite and mass level. Canada's Phase I measures did attempt to create a more balanced flow of information. Cigarette ads were pulled ("voluntarily") from broadcast advertising, and health warnings (however mild) were required on all packages. Canadian smoking rates did, in fact, decline: between 1966 and 1981, the proportion of male smokers dropped from $54 \%$ to $37 \%$. From one standpoint, therefore, the non-interventionist, informational approach was working.

To overcome the tobacco industry's political capacity to keep more aggressive control measures off the public agenda, therefore, it took more than reasoned presentation of health data. Rather, it required "entrepreneurial politics" to convince political leaders of tobacco's continuing threat to public health and of a communitarian obligation for more aggressive government action. This advocacy served as a political catalyst, engaging the paternalistic strain in Canadian values, and quickly leading to Type II legislation that went far beyond what American anti-tobacco activists were able to achieve, as well as to a significant expansion of Type III regulation.

As in the US, the Canadian political system is rather open to grass-roots lobbying pressures. On the other hand, Canadian public advocacy groups are generally but a "pale reflection of their US counterpart," ${ }^{21}$ partly because Canada's legislative process is inherently less adversarial. Yet Canadian Type II tobacco control lobbying was unusually aggressive, led by confrontational anti-smoking organisations, particularly the NonSmokers' Rights Association (NSRA). In order to promote legislative action, the NSRA relied on populist appeals to public opinion, intended, as its director put it, "to attach an air of criminality to tobacco industry executives and their dishonest, callous marketing practices". ${ }^{17}$ It ran a series of dramatic full-page ads reminiscent of American populism; one ad charged that 300000 Canadian tobacco deaths had been met with "legislative silence." Next, NSRA increased both its power and legitimacy by pursuing the traditionally low-key Canadian Cancer Society to join it in aggressive lobbying for change, mobilising a grassroots network of volunteers and physicians, ${ }^{16}$ forming a potent alliance which spurred significant Type II and III legislation. In 1988, the antismoking coalition convinced several major Canadian papers to voluntarily pull cigarette ads, ${ }^{17}$ as well as to endorse the Tobacco Products Control Bill. ${ }^{22}$ By the time this law approached the vote, all three major parties supported it. Its passage stimulated further legislation, such as the Non-Smokers' Rights Act, tax hikes, and local restrictive ordinances.

Canadian governmental structure, in which political power is far more concentrated and political parties far more cohesive than in the US, increased the anti-tobacco activists' ability to offset the Canadian tobacco industry's political clout. Once the national government's Health Minister was persuaded of the need to introduce anti-cigarette legislation, all that was required was the agreement of a handful of other key cabinet members - particularly the Prime Minister and Finance Minister. After securing this high-level support, political party discipline could then be trusted to help the government overcome whatever additional obstacles the tobacco companies could create.

By contrast, in the US, executive power to push anti-tobacco regulatory initiatives is dispersed among several federal departments: the Department of Agriculture, the Department of Health and Human Services (including the Food and Drug Administration), the EPA, the Occupational Safety and Health Administration (Department of Labor), and the Federal Trade Commission. Even if all of these semiautonomous bureaucracies could unite to seek tobacco legislation, their legislative proposal would still have pass through several Congressional committees and subcommittees, and finally through a Congress composed of members often more beholden to local constituencies (such as tobacco growers, or advertisers and publishers) and organised contributors than to political party leaders. Finally, from 1980 to 1992, the American presidency was controlled by a party openly hostile to both the principle of tax increases and the use of taxes to influence social behaviour.

Nevertheless, despite governmental fragmentation and restraint, we have seen that American political leaders, at the federal level and especially at the local level, have had little difficulty ignoring the tobacco industry's pleas when considering enactment of protective nonsmokers' rights policies, for these are consonant with American emphasis on individual autonomy. But they have been less willing than Canadian leaders, operating in a more communitarian, government-accepting culture, to search for consensus around the paternalistic policies of advertising bans and use-discouraging tax increases. In sum, in addition to governmental structure, political culture is essential in explaining marked differences in 
the direction of US and Canadian tobacco restrictions.

\section{Tobacco politics in France}

Even more than Canada, France has a statist political culture, in which government is expected to take a major role in shaping society. Compared to North America, government power in France is far more centralised. A highly respected, elite-educated bureaucracy dominates national policy-making, burdened far less by either particularistic interest group pressure or public activism, while French state involvement in business is more extensive and less controversial. At the same time, France spends more heavily on the welfare state, justified in part by a nationalistic concern for protecting French civilization. Finally, French culture is fiercely individualistic, at least in its resistance to moralistic social control of personal beliefs and lifestyle choices: "As a rule," notes one journalist, "the French detest being told what to do". ${ }^{23}$ In short, the French government is imbued with extraordinary legitimacy to determine large social goals, but not to control individual social behaviour.

France's tobacco control record has been less impressive than North America's. In 1976, more than ten years after US action and five years after Canada's first restrictions, France's activist Health Minister Simone Veil pushed through her country's first Type I legislation, banning broadcast and billboard advertising, calling for anti-smoking campaigns in schools; its mild warning label requirement was almost deceptive - "Overuse is dangerous." In addition, a moderate Type III law prohibited smoking on some government and transport facilities.

Veil's original regulation proposals had been harsher, but were seriously weakened in negotiations with French cabinet members, who were under pressure from SEITA, France's powerful state-owned tobacco monopoly. The Finance Ministry in particular was concerned over loss of revenues. In the years following passage of Veil's legislation, most of its provisions except for the broadcast ban, were only partially enforced (A Hirsch, unpublished observation). Education programmes were poorly financed and restrictions on use were largely ignored.

However, while the French government was not inclined to regulate SEITA seriously, it was more than willing to tax cigarettes for revenue purposes, especially after foreign brands fought their way into the French market. By 1986, French taxes made up $75 \%$ of the retail price of cigarettes, the second highest in Europe, ${ }^{24}$ and several times the American tax levels. Still, French smoking did not decline significantly between 1975 and 1985, as it did in North America.

The politics of French tobacco regulation has been quite distinct from its North American counterparts. The French citizenry were only peripherally involved, used mainly as an "opinion resource" providing poll information to elites. ${ }^{25}$ The anti-smoking movement itself had a decidedly elitist quality. Just as the French temperance movement of the 1930s and '40s had consisted largely of bourgeois wine-drinkers seeking to change the "unhealthy" habits of working class hard liquor consumers, so did the tobacco control movement tend to reflect the interests of better-educated, wealthier social groups. ${ }^{26}$

The principal anti-smoking lobbying organisation in France was distinctly un-populist: the Smoking or Health Medical Association consisted of a small group of elite doctors and researchers, who approached smoking strictly as a health issue. Founded in 1986, the Association assumed from the start that "some members will be in a position to contact influential persons" in government to advance their agenda. ${ }^{27}$ In that year, member Albert Hirsch wrote an official report to the Socialist Government, marking the tenth anniversary of the Veil law and calling for stronger restrictions on smoking and cigarette marketing (A Hirsch, unpublished manuscript). He went unheeded for two years, until a series of $L e$ Monde articles and medical press conferences - including two that featured French medical Nobel Prize winners - called for more aggressive action. By 1989, the Association had convinced Health Minister Claude Evin to back new proposals restricting advertising and use, and even higher taxes. Together, they drummed up media support that would exert pressure for acquiescence on a revenue-conscious Finance Minister, a Communications Minister concerned about freedom of speech, and a Sports and Culture Minister worried about events sponsorship. ${ }^{29}$

The French government apparently did not seriously consider philosophical arguments about paternalism $v s$ individualism or freedom of speech. Rather, the crucial issue was a technical, economic decision to remove cigarettes from the consumer price index, ${ }^{23}$ thereby allowing prices to increase without affecting cost-of-living indicators, hence wage and benefit levels. By March 1990, the French cabinet announced a package of Type II measures. The proposed legislation extended the ban on cigarette advertising from broadcasting to all print media (by 1993) and cinemas, prohibited product and event sponsorships under the name of tobacco products, required larger and more explicit health warnings on cigarette packets, and raised tobacco product prices by $15 \% .{ }^{25}$ In the French political system, once the executive has made its decision, full approval is swift; by December, despite protests from the tobacco industry, threats to pull out of sporting sponsorships, and advertising and media protests, the legislature had enacted the proposed tobacco restrictions. ${ }^{28,29}$

The highly centralised French policy-making style is also reflected in a Type III antismoking law which went into effect on 1 November 1992. The legislation extends a ban on smoking from cinemas, post offices and department stores to bars, shops, restaurants, work-shops, and offices (although the latter can still set aside smoking areas). This law was not a response to grass-roots pressure, but was 
rather a "top-down" effort by the French government to reduce smoking-related deaths. Thus, in contrast to the US, French smoking restrictions have been primarily motivated by the paternalistic goal of reducing health risks from smoking, not by grass-roots demands to protect non-smokers. Consequently, whereas compliance with democratically initiated smoking restrictions in Canada and the US appears to be quite high, ${ }^{30}$ the actual impact of France's "no smoking" law remains far from clear. ${ }^{31}$

Tobacco politics in Japan

In the spring of 1983, Atsuko Chiba ${ }^{32}$ wrote:

If you're a smoker, come to Japan. You can smoke in restaurants, office, trains, taxies, even hospitals. A non-smoker is an oddity in the business community, since... executives usually reach decisions after marathon meetings in smoke-filled conference rooms... Having quit smoking two years ago, I am suffering socially. Either friends no longer invite me to parties, knowing that I will complain about the smoke, or I shun gatherings where I cannot breathe.

She also noted that, while only $16.2 \%$ of Japanese women smoke, over $70 \%$ of men are regular smokers. "In no other country in the world is the two pack (or more) a day habit more prevalent than among Japanese men... Smoking is still very much a part of the Japanese businessman's lifestyle." ${ }^{33}$ In 1982, the Finance Minister boasted to the Diet of his heavy drinking and smoking, and a year later the Health Minister attributed his good health to smoking.

Like France, Japan has a highly centralised, elite-dominated political system with strong traditions of governmental control over business. Moreover, Japan is culturally a much more hierarchical society, in which citizens more readily defer to authority. Strongly entrenched norms of politeness govern personal and business relations. Thus, if the Japanese government ever decides to make a priority of reducing smoking rates or protecting non-smokers, it will probably have little difficulty in achieving its goals.

Nevertheless, as the above quote suggests, Japan has made less progress in discouraging smoking than any other wealthy industrialised nation. It continues to permit broadcast advertising, has not raised taxes in order to curb smoking (though cigarette taxes have been raised for revenue reasons), and has relatively few laws restricting smoking in public places. Japan also does the least to educate the public about smoking dangers. The first governmental report about cigarette risks was not released until 1987, and today Japanese cigarette packs say only: "For your health, avoid smoking too much." ${ }^{34}$ In short, despite awareness of health risks and growing social pressures to accommodate non-smokers, Japan remains a "smoker's paradise".

Japan does have a grass-roots anti-smoking movement; rallying behind the almost apologetic slogan "the right to dislike smoking," in 1978 it lobbied unsuccessfully to ban smoking in public places. In 1984, the All-Japan AntiSmoking Liaison Council (ASLC) led 40 of Japan's anti-smoking organisations in the country's first annual anti-smoking week. Through the mid-1980s, its most important achievement was to add a second non-smoking car to Japanese bullet trains - though most express trains still lacked special sections. By 1985, the Japanese government had still not enacted warning label requirements or broadcast advertising bans. Nonetheless, smoking did decline, dropping by 11.6 percentage points among males between 1976 and 1985, largely due to increased concern about health risks. $^{35}$ In addition, cigarette tax increases jumped to $60 \%$ of sale price by the mid-1980s. (However, these increases were not designed to discourage use.)

During the mid-1980s, the Japanese government made three major changes in the tobacco industry, all of which weakened the hand of anti-smoking activists. First, in response to declining domestic sales, the Finance Ministry began to promote cigarette exports actively; the government turned a deaf ear to the 500 Japanese anti-smoking organisations which protested that the new programme was "tantamount to exporting pollution." ${ }^{36}$ Second, in 1985 the Japanese tobacco monopoly was replaced by the new government-owned Japan Tobacco, Inc. In return for exclusive manufacturing rights in Japan, the new firm was required to buy all its tobacco leaf - Japan's second largest cash crop after rice - from local tobacco farmers who had successfully sought state protection. Finally, at the same time, US trade complaints led Japan to open its markets to foreign sales - a decision which the ASLC attacked as "deplorable at a time when the idea of a nonsmoking society is taking root in Japan ". ${ }^{37}$ Although both foreign and domestic cigarette producers voluntarily agreed to restrict TV advertising hours for the sake of young viewers, the entrance of foreign firms most of them American - led immediately to a dramatic increase in cigarette broadcast ads: by 1987 cigarettes had become the country's second most advertised product. ${ }^{38}$

The power of the tobacco industry and the reluctance of the Japanese government to impose smoking restrictions both remain striking. In October 1986, after the 60000-member ASLC raised the issue of passive smoking and health risks, Japan Tobacco, Inc, countered that there was insufficient evidence to make that link, while the government claimed it needed more time for research. ${ }^{39}$ Two years later, the ASLC found no success in pressuring the government for an advertising ban, a health warning label requirement, or removal of cigarette vending machines. ${ }^{40}$ In 1987, responding to its own report of the damage that pregnant women smokers cause their unborn children, ${ }^{41}$ the Ministry of Health announced a purely educational plan to distribute a manual of smoking guidelines in schools and encourage non-smoking sections in public places.

Of course, in Japan's deferential political system, even expression of government "concern" can have important consequences. On 1 
January 1989, the Tobacco Institute of Japan, an alliance of foreign and domestic producers, agreed to reduce cigarette advertising on television voluntarily by an additional eleven week-end hours, ${ }^{38}$ and to limit the size of newspaper ads. Subsequently, the tobacco industry agreed to restrict television advertising to programmes aired after $22: 55,{ }^{42}$ to devote more time to warning minors, and to indicate nicotine and tar content on packages. Nevertheless, these voluntary limits still fall short of even Type I legal measures in France and North America.

Progress was greater in the area of nonsmokers' rights, which impose controls over individuals, not on the politically potent tobacco industry. In January 1988, smoking was banned in all subway stations in Tokyo (largely for fire safety reasons), although cigarettes continued to be sold and advertised in these facilities. ${ }^{43}$ Yokahama instituted a similar policy. The following month, Japan Air Lines announced that smoking would be banned from three domestic air-routes with one-hour flight times, ${ }^{44}$ and adhered to its plan despite a threatened boycott by The Group to Think About Smoking Restrictions. ${ }^{45}$ By 1989, two major transit rail services had banned smoking on a number of routes. ${ }^{46}$

Given its striking power over social and economic policy, why has the Japanese government proceeded so timidly in dealing with tobacco control? It cannot be that Japan's government is indifferent to public health concerns. Prodded by citizen protests and lawsuits in the 1980s, it enacted environmental laws that within a short time transformed Japan from the most polluted industrial nation to the one dedicating the highest portion of GNP to pollution control. ${ }^{47}$ Furthermore, Japan has strict safety standards for a wide variety of foods, drugs, and other consumer products.

Nor is it the case that Japanese society is hostile to paternalism. By "western" standards, Japanese families and organisations engage in an extraordinary degree of freedominhibiting social control. Japan is pervaded by paternalistic policies, from "lifetime employment" guarantees, ${ }^{48}$ to corporate health and exercise programmes, to savings rate promotion $^{49}$ and judicial emphasis on apology and obligation rather than strictly legal rights and duties. ${ }^{50}$

Nor does the answer lie in ignorance or lack of concern. Though Japan's anti-tobacco lobby is politically weak, it has a substantial membership and has publicised smoking risks, publicly articulating the case for advertising and use bans and tax increases. Furthermore, the kinds of normative arguments used by North American tobacco companies - individualism, anti-statism and commercial freedom would not seem particularly powerful ones in the Japanese political culture.

We believe the answer to the Japanese puzzle lies in three different spheres: economic, cultural, and gender. The first major factor behind the weakness of Japanese tobacco legislation has to do with the tobacco industry's political and economic importance. Although Japan Tobacco, Inc, is private, $100 \%$ of its shares are still owned by the Finance Ministry, which is primarily concerned with both the revenues and the jobs provided by cigarettes. Furthermore, non-producer interests carry little political influence, since it is widely accepted that a primary task of the Japanese government is to foster the growth of key industries, not regulate them out of business. From this perspective, the reason Japan's measures have trailed behind those of other countries is not that libertarian arguments have beaten paternalistic ones, nor that empirical health issues are more contested in Japan, but rather that government support of business, perhaps above all other concerns, remains a powerful priority.

Secondly, in Japanese culture, obligations of reciprocity and loyalty are deemed inherent in the ongoing relationship between government and citizen, factory and community, capital and labour. In environmental disputes, both activists and the courts argued that industry and government had breached their traditional duties to protect loyal citizens and workers from chemical health hazards. However, where the link between state and society, employer and employee, is less clear, Japanese courts are less likely to impose legal obligations on business, ${ }^{48}$ and activists are less likely to appeal to public sensibilities. Precisely because the relationship between the tobacco industry and the consumer is more purely a market relationship and the risks of smoking are reasonably well-known, we speculate that it has been difficult to invoke Japanese paternalism effectively to limit cigarette marketing and use.

Another part of the answer to this puzzle lies in the politics of gender in Japan, a country in which almost two-thirds of adult men smoke, as compared with only $12 \%$ of women. ${ }^{51}$ Smoking in Japan is largely considered a male prerogative, and is an important part of business culture. Since Japanese society is especially male dominated, it is not surprising that anti-smoking activists, many of whom are female, have little clout.

\section{Conclusion}

Virtually all governments of industrialised democracies have publicised health risk information concerning cigarettes, compelled or induced tobacco companies to provide some kind of warning label on their products, and eliminated or limited their most effective marketing tool, broadcast advertising. Furthermore, this "information strategy" has an impact: cigarette use has generally declined in these nations, as has the social acceptability of smoking, a transformation which can only be expected to increase public pressure on government to regulate and tax tobacco ever more heavily.

In confronting the central issue, political leaders must consider both the degree and primary direction of state coercion. Governments are essentially asked to choose between two contrasting political philosophies. The 
classic liberal tradition is a two-edged sword. The more strongly a government embraces the values of individual choice and economic freedom, the more it is likely to ensure that the risks of tobacco use are clearly and widely publicised. Furthermore, the liberal state is more concerned with defending the rights of individuals who feel themselves in danger of "secondhand smoke." However, a liberal government is also more likely to let smokers choose to smoke, as well as to let cigarette producers advertise. The liberal state, moreover, comes to its regulatory decisions as a result of the pluralistic clash of interest groups; anti-smoking pressures originate in society, not in government.

On the other hand, a communitarian state would pursue smoking regulation in a more paternalistic manner, limiting cigarette marketing and use in an effort to save smokers and potential smokers from themselves. Like a concerned parent who discovers that his or her teenage son has started smoking, the communitarian state would consider it irresponsible not to take aggressive action in restricting this most foolish "freedom of choice." Such a government would also be far more inclined to compel tobacco companies to take responsibility for the dangers posed by their products, especially in light of their addictive properties; it would prohibit aggressive cigarette marketing, especially when it appeals to young, uneducated, or otherwise impressionable people. Furthermore, communitarianism would be manifested in very high levels of taxation, designed both to discourage young people from taking up smoking and to give regular smokers a strong economic incentive to quit. Where communitarianism and liberalism agree - albeit for somewhat different reasons is in restricting cigarette use to protect nonsmokers. Whereas the liberal state imposes zoning laws in order to protect the rights of individuals, the communitarian state views smoking in public areas as anti-social behaviour that should be marginalised and discouraged.

In formulating policies which necessarily limit the freedom of people to behave as they would like to, modern states must make choices about the pace of legal change: how forcefully and quickly should government try to enact its vision of the good society? In the communitarian tradition, the state would choose to err on the side of providing what it perceives to be a social good, while the liberal tradition emphasises the risks of government fallibility, choosing to err on the side of liberty and to accept a more gradual, social evolution of policy. Communitarians deplore the costs society must endure today. Liberals, sensitive to the alienation that can stem from coercive regulation, fear that even justified paternalism today can lead to authoritarianism tomorrow.

The most directly coercive and intrusive tobacco control laws are site-specific prohibitions on cigarette use, under which smokers are restricted, stigmatized, and temporarily banished from social interaction. Interestingly, the most aggressive imposition of zoning legislation has come from the US, where nonsmokers' rights are justified by liberal principles, "Your liberty to smoke stops when it impinges on my liberty to breath clean air". Tolerant, culturally pluralist Canada comes in a close second in restricting smokers. France and Japan, with comparatively weaker liberal traditions have been more timid in regulating smoking behaviour.

Perhaps France and Japan have lagged behind in use restriction simply because in these nations the social acceptability of smoking is greater, especially among elites, and anti-smoking sentiment is weaker. By 1980 , after two decades of widely publicised research linking smoking with heart and lung disease, adult male smoking rates in North America had declined to considerably less than $40 \%$ with relatively little government intervention; among educated elites, non-smoking had become the norm. By 1988, only $31 \%$ of American males smoked. ${ }^{52}$ In contrast, over half of French and Japanese men, especially businessmen and professionals, still smoke.

Furthermore, even in the US and Canada today, non-smokers' rights are far from universal. Many municipalities have not enacted zoning laws, most states allow businesses to set their own cigarette-use policies, and federal zoning rules apply only to certain places, such as aeroplanes and government offices. Nevada's law exempts gambling casinos in Reno and Las Vegas, while even in the non-smokers' stronghold of California, few municipalities have tried to ban smoking in bars. In sum, where coercive controls clash too strongly with folkways, democratic governments are less likely to enact them.

Another coercive anti-tobacco measure, but one more consistent with communitarian or paternalistic than liberal ideals, is heavy taxation, especially when tax rates are increased suddenly and substantially. Of the nations discussed, Canada has been the most willing to resort to rapid tax increases as a health policy to discourage youngsters from smoking. France, with a long tradition of tobacco taxation for revenue purposes, has also recently increased taxes specifically to reduce smoking. Even Japan's tobacco taxes (also mainly imposed for revenue) are far higher than those in the US where, aside from some state levies, they have generally not kept up with inflation. In 199192, average cigarette taxes per packet were US $\$ 3.26$ in Canada, $\$ 1.52$ in France, $\$ 1.06$ in Japan, and $\$ 0.46$ in the US. In explaining this pattern, America's liberal political tradition, with its antipathy to high taxes, seems to have been important.

Finally, the cigarette advertising ban is a policy choice that does not intrude deeply in daily life, but is nevertheless more consistent with paternalistic or communitarian than with liberal values, for such bans are highly coercive to the tobacco industry, and clash more strongly with both economic laissez-faire and freedom-of-speech ideals. In this policy sphere, Canada has been the front-runner, with France now close behind, while the US seems to have stopped with a broadcast ban

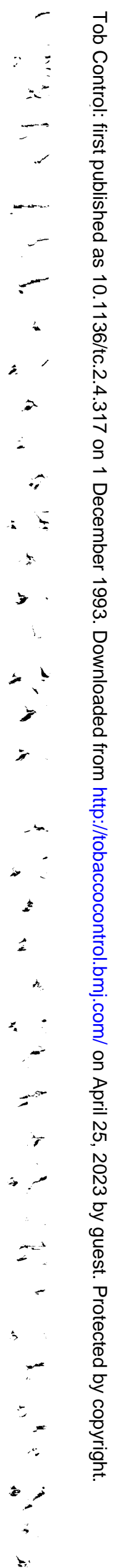


over 20 years ago. However, Japan comes in last; Japanese TV cigarette advertising actually increased in the $1980 \mathrm{~s}$, subject only to voluntary limitations on the hours of the day when cigarettes are advertised.

In terms of the pace of regulation, Japan has taken the slowest path again, despite its highly paternalistic and statist political tradition in other public policy areas. Canada stands at the other end of the continuum, having taken the most uniformly aggressive position for change on all fronts. France has been more ambivalent; after a slow start, its government recently was moved by public health advocates to impose heavy taxes, as well as advertising and use restrictions, though it has lagged in enforcing the latter.

The US appears to be the most schizophrenic regulator, moving rapidly on some fronts, slowly on others. More health conscious than most other societies, Americans nevertheless have been unable to pressure the federal government to restrict print advertising or tobacco promotional methods, while their government taxes cigarettes less than most industrialised democracies. Yet, while less aggressive than some countries in adopting paternalistic measures to protect smokers and potential smokers from "self-harm," American federal and especially local governments have been quick to adopt sweeping "zoning" laws designed to protect non-smokers from the risks of intermittent exposure to secondhand smoke which, while not insignificant, ${ }^{53}$ are surely less severe in most cases than risks from actually smoking. ${ }^{54}$

This "split personality" can be explained, at least in part, by political culture. Suspicious of government, Americans have generally opposed high taxes, while a strong tradition of judicially enforced constitutional protection of free speech has been the source of principled opposition to advertising restrictions. On the other hand, Americans have historically been quick to call upon government to protect their rights against personal intrusion or danger at the hands of business or fellow citizens, whether by lawsuits for damages, strict pollution-control regulations, or zoning laws. Typically, zoning laws do not carry heavy penalties, and almost always are enforced through private interaction. They can therefore be seen as consistent with the liberal state's commitment to socially motivated change, giving citizens the legitimating authority of legislation to define and defend their own "zones of freedom".

In looking to the future of American smoking laws, it is important to recognise that the longer-term goals of non-smokers' rights activists tend to be deeply paternalistic. Although coercive zoning rules have been justified within the liberal tradition, they are widely regarded as a means to increasingly broader ends: the social marginalisation of smokers, the delegitimisation of cigarettes, and ultimately a smoke-free society. Thus, local anti-smoking groups have also pushed for laws restricting access to cigarettes (eg, through vending machines) and other sales and promotional methods. As smoking rates in the US continue to decline, and smokers are increasingly viewed as a deviant, vulnerable, foolish, or even a "handicapped" minority, Americans are likely to accept, if not demand, more aggressively paternalistic cigarette laws.

The authors wish to thank Dennis Galvan and Tom Burke fo their research and editorial assistance, as well as the Universit of California Tobacco-Related Disease Research Project. This article draws extensively on material published elsewhere. ${ }^{5}$

1 Wilson JQ. The politics of regulation. New York: Basic Books, 1980

2 Leichter H. Free to be foolish: politics and health promotion in the United States and Great Britain. Princeton: Princeton University Press, 1991.

3 Pertschuk M Giant killers, New York : WW Norton, 1986.

3 Pertschuk M. Giant killers, New York: WW Norton, 1986. advertising regulation. F Public Policy Marketing, 1988; 7: $49-64$

5 Mitchell ML, Mulherin JH. Finessing the political system: the cigarette advertising ban. Southern Economic $\mathcal{F} 1988$ 54 (4) $855-62$.

6 Smoking during the $80 \mathrm{~s}$ : a waning flame. 7 Natl Cancer Inst $1990 ; 82$ (3).

7 Schelling T. Addictive drugs: the cigarette experience, RAND Drug Policy Research Center, 1991.

8 Beltramini RF. Perceived believability of warning label information presented in cigarette advertising. $f \mathrm{Ad}$ vertising 1988 ; 17 (1) 26-32.

9 Popper ET, Murray KB. Communication effectiveness and format effects on in-ad disclosure of health warnings. $\mathcal{J}$ format effects on in-ad disclosure of health

10 Nomani AQ. Smoking sparks tiff with airline crews. Wall Street fournal. 18 December 1990, p B1.

11 Glantz S. Achieving a smokefree society. Circulation, October 1987, v 76

12 Altman LK. The evidence mounts on passive smoking, New York Times, 29 May 1990, pp C1, C8.

13 Kerr R. EPA smoke report should fuel the fire. San Francisco Examiner, 2 September 1990, p A3.

14 Rosewicz B, Karr AR. Smoking curbs get a new lift from EPA plan. Wall Street fournal, 21 June 1990, p B1.

15 Brandt A. The cigarette, risk and American culture. Daedalus, Fall 1990

16 Lachance V, Collishaw N. Tobacco control in Canada. Proceedings of the European Conference on Tobacco Priorities and Strategies. The Hague, 1-3 November 1989

17 Mintz M. No ifs, ands or butts. Washington Monthly, July-August 1990 , pp 30-7.

18 Grossman M, Price P. Tobacco smoking and the law in Canada. Toronto: Butterworths, 1992.

19 Lipset SM. Continental divide: the values and institutions of the United States and Canada. New York: Routledge, 1991.

20 Grimond J. For want of glue: a survey of Canada. The Economist, 29 June 1991.

21 Ostry S. Government intervention: Canada and the United States compared. In: R Landed, ed. Canadian politics: comparative reader. Scarborough, Ontario: Prentice-Hall, 1985.

22 Kyle K. Canada's tobacco legislation: a victory for the health lobby. Health Promotion, Spring 1990, pp 9-12. 23 Tempest R. France's anti anti-smoking campaign. San Francisco Examiner, 6 June 1990.

24 O'Hagan J. Carey KM. The proposal for upward alignmen of tobacco taxes in the European Community: a critique. Br Tax Rev 1988; 8: 329-48.

25 Ibrahim Y. French plan to restrict ads: less wine and no smoking. New York Times, 29 March 1990, p D1.

26 Prestwich P. Drink and social reform, Palo Alto: Society for the Promotion of Science and Scholarship, (1988), as cited in review by T Brennan. $f$ Social Hist $1990 ; 23$ (4) 859-61.

27 Freour P. French doctors to the aid of smokers. World Health Forum 1986; 7.

28 Riding A. France is new front in battle over tobacco ads. New York Times, 9 April 1990, p D8.

29 French ban on tobacco ads. New York Times, 7 June 1990 $\mathrm{p}$ D2

30 Kagan RA, Skolnick J. Banning smoking: compliance without enforcement. In: $\mathbf{R}$ Rabin, S Sugarman, eds. Smoking policy : law, politics \& culture. New York: Oxford University Press, 1993.

31 Stubbed out. The Economist, 7 November 1992.

32 Chiba A. Japan clouded by smoke. Mainichi Daily News, 16 May 1983.

33 Blum A. Japan: land of the rise in lung cancer. NY State $\mathcal{F}$ Med, July 1985

34 Smokers on the defensive in Japan. Japan Economic Newswire 16 February 1988

35 Tanifuji T. Tobacco. fapan Economic Almanac, 1986; pp 182-3.

36 Cigarette export ban demanded. Fapan Times, 13 January 1984.

37 Not all open markets healthy, Reagan told. fapan Times, 11 September 1985 . 
38 Television remains a fertile field for tobacco ads, antismokers say. Japan Times, 10 February 1989

39 Nonsmokers awaken to new dangers. Mainichi Daily News, 7 November 1986 .

40 Anti-smoking group requests government action. Japan Times, 15 April 1988.

41 Government releases study on smoking. Mainichi Daily News 18 October 1987

42 Shaw F. Cigarette smoking, trade and health $\mathcal{f}$ Am Chamber of Commerce in fapan, September 1989.

43 Smoke ban a success. Mainichi Daily News, 8 January 1988. 4 Smoking to be banned on three short JAL routes. Asahi Evening News, 19 February 1988.

45 Group bids JAL rescind smoking ban on short hops. fapan Times, 3 March 1988.

46 Japan Railway Institute partial smoking prohibition. fapan Times, 16 June 1989

47 Upham F. Law and social order in postwar fapan, Cambridge: Harvard University Press, 1987.

48 Upham F. Japan: a different vision of law and justice. The Responsive Community, 1991.
49 Bayley D. Forces of order: policy behavior in fapan and the United States. Berkeley: University of California Press, 1976.

50 Wagatsuma $\mathrm{H}$, Rossett $\mathrm{A}$. The implications of apology: law and culture in Japan and the US, Law Soc Rev, 1986;20. 51 Prakash S, Steidlemeier P. Cigarette smoking and public health : part II. In: $U p$ against the corporate wall, 5 th edn Englewood Cliffs, New Jersey: Prentice-Hall, 1991.

52 US smoking rate declines to $28 \%$, survey says. New York Times, 9 November 1991, p 9 .

53 Siegel $\mathrm{M}$. Involuntary smoking in the workplace: a review of employee exposure and health effects. FAMA 1993; 270: $490-3$.

54 Bichop J. Statisticians occupy front-line in battle over passive smoking. Wall Street fournal, 28 July 1993, p B1.

55 Kagan RA, Vogel D. The politics of smoking regulation: Canada, France and the United States, In: R Rabin, SD Sugarman eds. Smoking policy: law, politics $\mathcal{E}$ culture. New York: Oxford University Press, 1993.

Foreign language abstracts of this paper will appear in vol 3, issue 1 of Tobacco Control
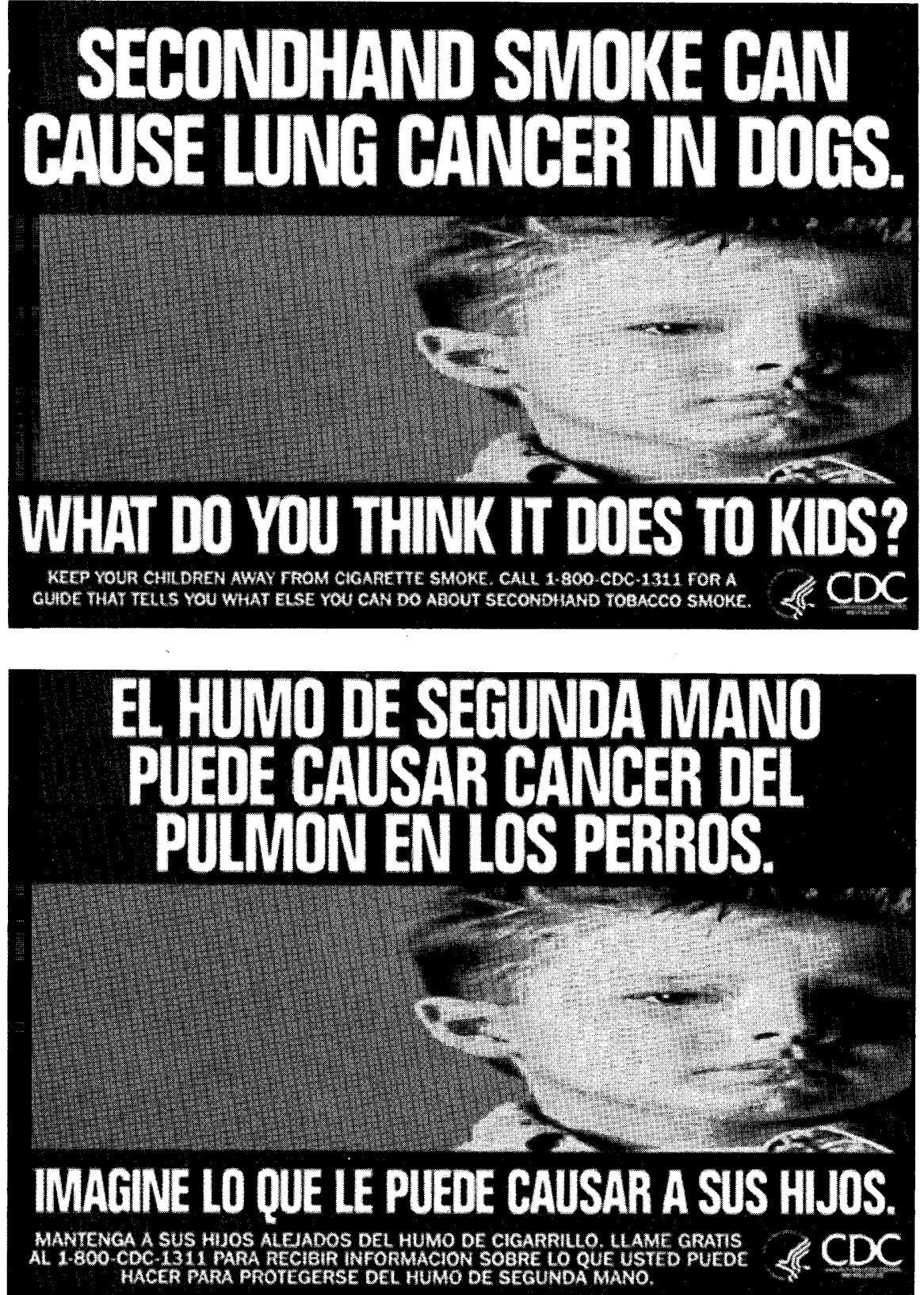

This sign is part of the second wave of materials on secondhand smoke from the US Centers for Disease Control and Prevention's Office on Smoking and Health. For more information, contact the Office on Smoking and Health, Centers for Disease Control and Prevention, 1600 Clifton Road, NE, Atlanta, Georgia 30333, USA (tel. (1 404$)$ 4885705 ; fax. (1 404) 4885938 ). 